\title{
Consensus on the treatment of autoimmune bullous dermatoses: bullous pemphigoid, mucous membrane pemphigoid and epidermolysis bullosa acquisita - Brazilian Society of Dermatology*
}

\author{
Claudia Giuli Santi ${ }^{1}$, Alexandre Carlos Gripp ${ }^{2}$, Ana Maria Roselino ${ }^{3}$, Danielle Santana Mello², \\ Juliana Olivieri Gordilho ${ }^{1}$, Paula Figueiredo de Marsillac ${ }^{2}$, Adriana Maria Porro ${ }^{4}$
}

DOI: http:/ / dx.doi.org/10.1590/abd1806-4841.2019940207

\begin{abstract}
Bullous pemphigoid, mucous membrane pemphigoid and epidermolysis bullosa acquisita are subepidermal autoimmune blistering diseases whose antigenic target is located at the basement membrane zone. Mucous membrane pemphigoid and epidermolysis bullosa acquisita can evolve with cicatricial mucosal involvement, leading to respiratory, ocular and/or digestive sequelae with important morbidity. For each of these dermatoses, a literature review covering all therapeutic options was performed. A flowchart, based on the experience and joint discussion among the authors of this consensus, was constructed to provide treatment orientation for these diseases in Brazil. In summary, in the localized, low-risk or non-severe forms, drugs that have immunomodulatory action such as dapsone, doxycycline among others may be a therapeutic option. Topical treatment with corticosteroids or immunomodulators may also be used. Systemic corticosteroid therapy continues to be the treatment of choice for severe forms, especially those involving ocular, laryngeal-pharyngeal and/or esophageal mucosal involvement, as may occur in mucous membrane pemphigoid and epidermolysis bullosa acquisita. Several immunosuppressants are used as adjuvant alternatives. In severe and recalcitrant cases, intravenous immunoglobulin is an alternative that, while expensive, may be used. Immunobiological drugs such as rituximab are promising drugs in this area. Omalizumab has been used in bullous pemphigoid.
\end{abstract}

Keywords: Autoimmunity; Basement membrane; Skin diseases

\footnotetext{
Received 14 September 2018.

Accepted 30 January 2019.

* Work conducted at the Sociedade Brasileira de Dermatologia, Rio de Janeiro (RJ), Brazil.

Financial support: None.

Conflict of interest: None.

Department of Dermatology, Hospital das Clínicas, Faculdade de Medicina, Universidade de São Paulo, São Paulo (SP), Brazil.

Department of Dermatology, Hospital Universitário Pedro Ernesto, Universidade do Estado do Rio de Janeiro, Rio de Janeiro (RJ), Brazil.

Division of Dermatology, Department of Medical Clinics, Faculdade de Medicina de Ribeirão Preto, Universidade de São Paulo, Ribeirão Preto (SP), Brazil.

Department of Dermatology, Escola Paulista de Medicina, Universidade Federal de São Paulo, São Paulo (SP), Brazil.
} 


\section{BULLOUS PEMPHIGOID $\nabla$}

\section{INTRODUCTION}

Bullous pemphigoid (BP) accounts for $80 \%$ of subepidermal bullous dermatoses. It typically presents as generalized pruritus and tense bullous eruptions and may be associated with a $20 \%$ to $40 \%$ mortality rate. It primarily affects those aged above 70 years, and its annual incidence is estimated to be at least 13 to 62 new cases per million persons, rising significantly after 60 years old. ${ }^{1-3}$

\section{ETIOPATHOGENESIS}

In the etiopathogenesis of $\mathrm{BP}, \mathrm{IgG}$ autoantibodies are produced against antigens of the basement membrane zone (BMZ) -180kDa and 230kDa -collagen XVII, COL17 or BPAg2, and BPAg1, respectively. BP180 is the most relevant antigenic determinant, whereas BP230 appears to be more related to cytoskeletal function and signaling of the dermoepidermal transition. The involvement of mast cells and IgE in the development of BP lesions has recently been described. . $^{4-19}$

The association of malignancies with $\mathrm{BP}$ is likely to be related to the incidence of both diseases in the elderly, although some reports have suggested an increase in the frequency of certain cancers, such as those in the digestive tract, lung, and bladder and lymphoproliferative diseases. ${ }^{20,21}$

$\mathrm{BP}$ is rarely described in patients with inflammatory or autoimmune diseases. In certain patients, it appears to be triggered by trauma, burns, radiotherapy, or irradiation by ultraviolet rays. BP has also been observed in association with psoriasis and lichen planus. ${ }^{22}$

In some patients, systemic medications may lead to the development of BP, including diuretics (furosemide), antibiotics (amoxicillin, ciprofloxacin), potassium iodide, and captopril. The mechanism by which drugs induce BP has not been determined..$^{23}$

Of greater interest, BP has been associated with neurological diseases, such as dementia, stroke, multiple sclerosis, epilepsy, and Parkinson disease, but the underlying pathophysiological mechanism is not completely understood. It is possible that the BP antigens $\mathrm{BPA}_{1}$ and $\mathrm{BPA}_{2}$ act as autoreactive antigens in the central nervous system and in tegument. ${ }^{24-36}$

The HLA class II DQB1*03:01 allele is more prevalent in Caucasian patients with BP than in the general population and has also been associated with neurological diseases. ${ }^{37,38}$

\section{CLINICAL CONDITION}

The tegumentary manifestations of BP are extremely polymorphic. In the non-blistering phase, the signs and symptoms are usually nonspecific, presenting as isolated pruritus, sometimes intractable or associated with excoriations, papules, or urticarial lesions, which may persist from weeks to months. Vesicles or blisters on apparently normal or erythematous basis, in addition to infiltrated papules and plaques that occasionally assume annular and figurative patterns, can characterize the bullous phase of BP. The blisters are smooth, with diameters ranging from 1 to $4 \mathrm{~cm}$, containing clear fluid, leaving crusted and eroded areas. The lesions often have a sym- metrical distribution, predominating in the limb flexures and chest. Localized involvement is uncommon. ${ }^{31}$ Oral involvement is observed between $10 \%$ and $30 \%$ of affected patients. The eyes, nose, pharynx, esophagus, and anogenital regions are rarely affected. 1,18,22-24,39

\section{LABORATORY DIAGNOSIS}

The diagnosis of BP is based on clinical characteristics and, more importantly, direct immunofluorescence (DIF) and indirect immunofluorescence (IIF) findings by microscopy; the presence of antibodies against the BP180 peptide by enzyme-linked immunosorbent assay (ELISA) confirms the diagnosis. In most cases, immunofluorescence is essential and sufficient for the correct classification of subepidermal bullous dermatoses. Nevertheless, particularly in patients with negative DIF and IIF findings, additional immunoblotting assays are useful and required to demonstrate the presence of autoantibodies in the patient's serum, based on disease target antigens (BP180 and BP230). In the absence of the onset of bullous lesions, such as in the early stages or atypical variants of the disease, the diagnosis of BP depends solely on positive results by DIF or IIF. ${ }^{39-41}$

In most patients, DIF of non-impaired perilesional skin will demonstrate linear and continuous IgG or $\mathrm{C}_{3}$ deposition along the BMZ. Furthermore, the salt-split skin (SSS) IIF technique, when treating normal human skin with $1 \mathrm{M} \mathrm{NaCl}$, followed by incubation with the patient's serum, may be useful in distinguishing BP from other subepidermal bullous autoimmune diseases, primarily epidermolysis bullosa acquisita and bullous lupus erythematosus. ${ }^{40,41}$ In BP, immune deposits are found on the epidermal side or on both sides of the cleavage (dermal and epidermal). In $60 \%$ to $80 \%$ of patients, IgG autoantibodies and, less frequently, $\operatorname{IgA}$ and $\operatorname{IgE}$ are circulating; these autoantibodies also often bind to the cleavage on the epidermal side. ${ }^{23}$

ELISA using recombinant proteins that contain specific regions of BP antigens (eg, BP180 domain NC16A and the C-terminal portion of $\mathrm{BP} 180$ or $\mathrm{BP} 230$ ) is useful for the $\mathrm{BP}$ diagnosis. The determination of antibodies against BP180 and BP230 may be necessary to confirm the diagnosis; rarely, $\mathrm{BP}$ patients have antibodies against desmogleins - ie, pemphigus antigens. ${ }^{31,41,42}$ Serology may also be used for therapeutic follow-up, especially at the time of treatment discontinuation. ${ }^{33}$

\section{TREATMENT}

The treatment of $\mathrm{BP}$ is based more on clinical experience than on controlled studies. For the extensive form, systemic corticosteroids are the main option, wherein a regimen of oral prednisone of 0.5 to $0.75 \mathrm{mg} / \mathrm{kg} /$ day is recommended. Large controlled studies have reported the value of potent topical corticosteroids, which also appear to control generalized BP with similar efficacy as systemic corticosteroids and with few side effects. ${ }^{23,43}$ However, the refractory nature of some patients to corticosteroids merits further study. ${ }^{44,45}$ 


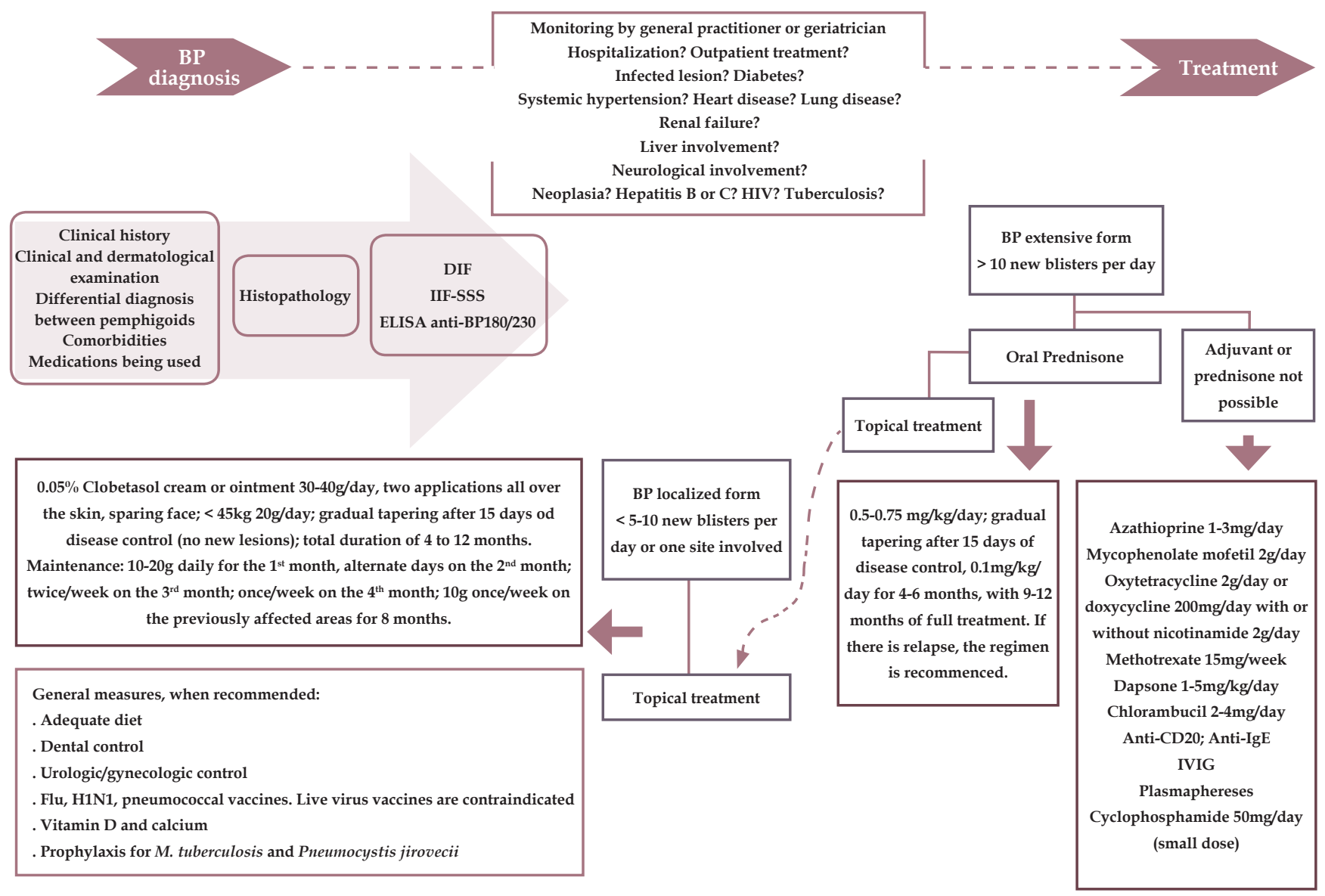

DIF - direct immunofluorescence; ELISA - enzyme-linked immunosorbent assay; IIF - indirect immunofluorescence; IVIG - intravenous immunoglobulin

FigurE 1: The flowchart represents the modified consensus of bullous pemphigoid (BP) treatment

Eventually, pulse therapy with methylprednisone may be required to control the disease more rapidly. The use of immunosuppressive drugs has been discussed; certain groups advocate their use only as second-line therapy, when monotherapy with corticosteroids fails or if there is any contraindication. The most frequently used agents are azathioprine, mycophenolate mofetil, methotrexate, chlorambucil, and cyclophosphamide. ${ }^{23,43}$ Low doses of cyclophosphamide may have benefits. ${ }^{46}$ The combination of nicotinamide and minocycline or tetracycline can be used as a therapeutic alternative.
Dapsone can be administered, especially when there is mucosal involvement, and the value of topical immunomodulators, such as tacrolimus, should be confirmed..$^{23,43,47}$ In cases of treatment resistance, intravenous immunoglobulin, plasmapheresis, or anti-CD20 immunotherapy (rituximab) may be prescribed. Based on the immunopathogenesis of BP, new compounds are being proposed..$^{47-49}$

Recently, a European consensus was developed for the treatment of $\mathrm{BP}^{43}$ The figure 1 that is presented here depicts this consensus with modifications, in addition to the revisions that have been incorporated for the treatment of BP. ${ }^{43-49}$ 


\section{MUCOUS MEMBRANE PEMPHIGOID $\boldsymbol{\nabla}$}

\section{INTRODUCTION}

Mucous membrane pemphigoid (MMP), also known as cicatricial pemphigoid, refers to a group of chronic autoimmune diseases that predominantly affect the mucous membranes and, occasionally, skin. ${ }^{50}$ It is part of a group of autoimmune dermatoses that present with subepidermal bullous lesions, characterized by the formation of antibodies against structures of the basement membrane zone (BMZ). In MMP, antibodies bind more frequently to BP-180 and laminin 332 (laminin 5) ${ }^{51}$ Scarring of lesions on the mucous membranes is common - hence, the term "cicatricial" - which may lead to decreased visual acuity, blindness, supraglottic stenosis with hoarseness, or airway obstruction..$^{50}$

\section{EPIDEMIOLOGY}

MMP usually has a late onset, between age 60 and 80 years. Women appear to be more commonly affected than men, from 1.5 to 2 times more frequently, with no racial or geographic preference. European data show an incidence of approximately 1:1,000,000 people annually. The initial signs and symptoms may be subtle and non-specific, with irreversible and often debilitating consequences. It is associated with high morbidity and mortality if treatment is not initiated early and aggressively. ${ }^{52}$

\section{ETIOPATHOGENESIS}

MMP is characterized by the linear deposition of $\operatorname{Ig} G$, IgA, or $\mathrm{C} 3$ along the epithelial basement membrane area. ${ }^{53}$ Current evidence suggests that this process develops as a consequence of the loss of immune tolerance to structural proteins of the epidermal basement membrane, culminating in the development of circulating autoantibodies that bind to the epidermal basement membrane, causing inflammation and weakening the adhesion of the overlying epidermis. ${ }^{52}$

Studies have shown that the target antigens in the epithelial basement membrane area include bullous pemphigoid antigen 1 (BP230), bullous pemphigoid antigen 2 (BP180), laminin 5 ( $\alpha 3$, $\beta 3, \gamma 2$ chains), laminin 6 ( $\alpha 3$ chain), type VII collagen, and the $\beta 4$ integrin subunit. ${ }^{53} \mathrm{BP} 180$ is a transmembrane protein that crosses the lamina lucida and protrudes into the dense lamina of the epidermal basement membrane zone; it is usually the target antigen in approximately $70 \%$ of MMP patients. Serum from patients with generalized and ocular MMP recognizes the $\beta-4$ integrin subunit, whereas serum from those with oral MMP recognizes the $\alpha-6$ integrin subunit.

The pathogenicity of anti-laminin 332 has been documented in vivo. Passive transfer of anti-laminin 332 IgG to mice induces subepidermal blistering on the skin and mucous membranes, mimicking the clinical, histopathological, and immunological characteristics of patients with MMP. ${ }^{54}$ Fibroblasts also appear to be activated, secondary to the production of cytokines, such as transforming growth factor beta, which is known to induce fibrosis. The collagen that is produced can lead to scars. Several studies have shown a predominance of CD4 T lymphocyte and Langerhans cell infiltrates in the conjunctiva of patients with MMP, indicating the involvement of cellular immunity in its pathogenesis. Studies have linked MMP and the human leukocyte antigen (HLA) class II HLA-DQB1 * 0301 allele. ${ }^{55}$

\section{CLINICAL CONDITION}

MPP can affect the mucous membrane from several sites, occasionally with skin involvement. It is a chronic, progressive condition that most often affects the oral mucosa (85\% of patients), followed by the ocular conjunctiva (65\%), nasal mucosa $(20-40 \%)$, skin $(25-30 \%)$, anogenital region and pharynx (20\%), larynx (5-15\%), and esophagus (5-15\%). There is a wide range in the variability and severity of presentations among patients, who can present with localized and generalized involvement. Those who present with only oral mucosal or skin involvement with a lower tendency toward scarring are defined as "low risk," whereas in patients who are at "high risk," the disease occurs in general ocular, esophageal, laryngeal, nasopharyngeal, and anogenital mucosae. The propensity for generating scars in these sites is associated with a poor prognosis, despite treatment. ${ }^{56}$

Involvement of the oral mucosa typically manifests as erythematous plaques and erosions that are covered by pseudomembranes, most commonly located on the gum and palate and less frequently on the lips, tongue, and cheek mucosa. Gingival lesions are often described as desquamative gingivitis, also found in lichen planus and pemphigus vulgaris. The most common ocular lesions are conjunctival inflammation and erosions, forniceal shortening with formation of symblepharon, trichiasis, entropion, and cornea neovascularization, which may result in blindness. The most frequently affected skin areas are the scalp, face, neck, and upper chest. Lesions usually present as erythematous plaques, with the formation of recurrent blisters and erosions and consequent atrophic scarring. ${ }^{55}$ Scarring of the laryngeal mucosa can lead to hoarseness, cough, dyspnea, and even acute respiratory failure. Scarring of the anogenital mucosa usually presents as blisters, erosions, and scars and can significantly affect a patient's quality of life. ${ }^{56}$ Esophageal involvement in MMP is rare and is observed in patients with disseminated disease. The most common changes that occur are multiple membranes and esophageal constriction. .5, 56

A diagnosis of MMP should be considered in patients with bullous lesions or erosions that compromise predominantly mucous membranes. The main differential diagnoses in MMP include bullous pemphigoid, epidermolysis bullosa acquisita, and linear IgA dermatosis. When there is oral involvement, MMP lesions should be differentiated from pemphigus vulgaris, bullous pemphigoid, erythema multiforme, and erosive lichen planus. Ocular cicatricial lesions in MMP should be distinguished from the scarring lesions of severe chronic infectious conjunctivitis, ophthalmic solution-indu- 
ced ocular pseudopemphigoid, and scarring lesions in more severe cases of Stevens-Johnson syndrome and toxic epidermal necrolysis. Generalized skin bullous lesions are impossible to distinguish from those in bullous pemphigoid; however, the predominance of mucosal lesions, associated with a tendency toward scar formation, favors a diagnosis of MMP. ${ }^{53,55}$

\section{LABORATORY DIAGNOSIS}

The diagnosis of MMP is based on the patient's clinical presentation and histopathological characteristics. In these cases, tissue biopsy is extremely important, because the epithelium of MMP patients tends to move easily, rendering the sample inadequate if it is not performed correctly. ${ }^{56}$

\section{Histopathology}

Histopathology by hematoxylin-eosin staining typically reveals the presence of subepithelial blisters with or without significant inflammatory infiltrates, which may be composed of eosinophils, lymphocytes, and neutrophils, similar to the changes that are observed in other forms of pemphigoid. A second sample should be obtained from perilesional tissue that is adjacent to a new vesicle to complement the findings by microscopy. ${ }^{57}$

\section{Direct immunofluorescence}

Direct immunofluorescence of perilesional skin or mucosa shows continuous deposits of IgG, IgA, or C3 on the BMZ. Detection of these immune deposits establishes the disease's autoimmune nature, and immune deposits that are characteristic of the BMZ distinguish MMP from other diseases with mucocutaneous involvement. ${ }^{53}$

\section{Indirect immunofluorescence}

Indirect immunofluorescence is used to detect circulating antibodies in patient serum. To determine the BMZ components that are targeted by autoantibodies, a procedure, known as salt-split, is performed. This process results in separation of the epithelium from the connective tissue at the site of the lamina lucida, exposing $\mathrm{BMZ}$ antigens and resulting in greater sensitivity for the detection of serum binding antibodies that are directed against the substrate. ${ }^{57}$ After separation of the layers, the epithelial side ("ceiling" pattern, classic in bullous pemphigoid), the dermis side ("floor" pattern, classic in epidermolysis bullosa acquisita), or their combination (ceiling and floor pattern) can be visualized, reflecting the various autoantigens that are recognized by these autoantibodies. ${ }^{53}$

\section{TREATMENT}

MMP is a chronic, rare autoimmune bullous disease that can have a significant impact on a patient's quality of life. Careful clinical examination of the skin and all mucosal surfaces should be performed, and complaints that are related to other systems should be investigated, such as visual impairment, epistaxis, hoarseness, cough, dysphagia, weight loss, dysuria, and rectal bleeding. The aim is to detect cutaneous and mucosal involvement early, due to the risk of the chronic inflammatory processes evolving, causing tissue destruction, scarring, and functional limitation.

A multidisciplinary approach is often required to minimize the risk of the adverse consequences of this disease. Collaboration between dermatologists, dentists, ophthalmologists, otolaryngologists, urologists, intensivists, and gastroenterologists can contribute to a better therapeutic outcome. The main goals of treatment are to improve symptoms, halt disease progression, and prevent the adverse sequelae of chronic inflammation and tissue scarring. Selection of the appropriate treatment depends on several factors, including the site that is involved, disease severity, and its progression. ${ }^{50,53}$

Patients can be divided into a low-risk group, with lesions that are restricted to the oral mucosa, and a high-risk group, with ocular, pharyngeal, laryngeal, esophageal, and genital lesions. The treatment for the low-risk group is conservative, prioritizing topical treatment when possible, whereas in the high-risk group, treatment should be aggressive, with early initiation of systemic agents. ${ }^{53,58}$

Due to the absence of large, multicenter, randomized, and controlled clinical trials for this disease group, the treatment strategy is based on expert experience and literature reports. . $^{5,59}$

\section{Topical treatment \\ Corticosteroids}

Moderate- to high-potency topical corticosteroids are the first-line treatment for low-risk patients who have the disease limited to the oral mucosa with or without cutaneous involvement. A conservative approach is recommended, because there is less risk of scarring in these regions. These agents may also be useful as adjunctive therapy in the most severe cases, constituting important components of the therapeutic arsenal. Corticosteroid gels, ointments, or elixirs can be used 2 to 3 times a day. Gels are applied more easily and better tolerated in the oral cavity. It is important to guide the patient to dry the mucosa before application, rub the medication gently at the site for 30 seconds, and refrain from eating or drinking for 30 minutes. One of the applications should be performed before bedtime, because oral secretions are diminished during sleep. This step may allow the medication to remain longer in the treated area. ${ }^{60}$

Alternative methods of administering corticosteroids include trays that are made by dentists to provide medicines under occlusion, for patients with gingival involvement. Trays should be inserted into the dental arch and held for 10 to 20 minutes. ${ }^{60,61}$

If the patient does not respond adequately to topical therapy, injections of intralesional corticosteroids, which have had some success, may be used. The application should be superficial, just below the erosions; if it is deeper, it may increase the risk of mucosal atrophy. Injection of triamcinolone hexacetonide at 5 to $10 \mathrm{mg} / \mathrm{ml}$ every 2 to 4 weeks is recommended. The total dose that is administered on a per-session basis should not exceed $20 \mathrm{mg} .53,60$

Some adverse effects of topical corticosteroids are known, such as mucosal atrophy, oropharyngeal candidiasis, and reactivation of herpes simplex virus. Usually, patients improve in several weeks with the use of topical corticosteroids. As improvement occurs, the patient can gradually decrease the frequency of applications and substitute them for less potent agents, avoiding mucosal atrophy. If treatment discontinuation is not possible due to relapses, the patient should be maintained with the lowest effective topical or systemic maintenance regimen. . $00,62,63^{-1}$ 


\section{Tacrolimus}

Topical tacrolimus, a calcineurin inhibitor, appears to be effective in patients with localized oral disease, effecting complete remission within 2 to 3 months of treatment. However, topical corticosteroids are more effective. The high cost of tacrolimus in relation to many topical corticosteroids makes it difficult for some patients to use this therapy. Tacrolimus is generally indicated for patients who experience relapse of lesions as the application frequency and potency of the corticosteroids are reduced. A maintenance regimen, in which corticosteroid treatment is alternated with topical tacrolimus, may help keep the patient in remission and reduce the risk of the long-term side effects of corticosteroids. Topical tacrolimus $0.1 \%$ ointment should be initially applied twice daily, according to the patient's tolerance, because a transient burning sensation may occur soon after application. ${ }^{64-66}$

\section{Oral care}

When there is oral cavity involvement, the patient needs to be encouraged to exercise good hygiene. Frequent toothbrushing is indicated using soft-bristled brushes, proper technique, toothpaste that does not contain sodium lauryl sulfate, alcohol-free mouthwash, and flossing to avoid plaque build-up, acceleration of dental caries, and loss of gums and teeth. Topical anesthetics (e.g., lidocaine) may be used to reduce pain by applying them to lesions before meals, brushing, dental procedures, and other occasions. Mild debridement of necrotic mucosal tissue can be performed to prevent infection. Oral cavity trauma using ill-fitting dentures can lead to the formation of new erosions. Thus, regular dental evaluations are imperative in patient care. ${ }^{60,67}$

\section{Extraoral care}

In addition to pharmacological treatment, other interventions may be useful in the management of patients with extraoral involvement. Early referral to specialists is essential to prevent scars and sequelae in these regions. When there is nasal involvement, lavage with saline, application of emollients, and the use of corticosteroids in spray form may be useful. Esophageal involvement justifies a liquid-pasty diet, measures for preventing gastroesophageal reflux, and dilatation of stenosis. When there is involvement of the anogenital region, corticosteroids, and even topical calcineurin inhibitors, can be indicated. The patient should be guided to consume a laxative diet that is rich in water and fiber intake for digestion and stool excretion. ${ }^{60,67}$

\section{Systemic treatment \\ Antibiotics}

Antibiotics, such as dapsone, other sulfonamides, and tetracyclines with or without nicotinamide, may be effective in the treatment of MMP. Dapsone is often used as first-line therapy to control localized conditions that have not responded to local therapy or extensive, slowly progressing conditions that benefit from systemic agents. If there is a partial response, systemic corticosteroids or immunosuppressive agents may be combined. Local therapy should be maintained as an adjunct.

Most patients respond to dosages of dapsone of between 50 and 200mg per day. Therapy should be started at a low dose, 25 to $50 \mathrm{mg}$ per day, and gradually increased ( 25 to $50 \mathrm{mg}$ per week), depending on the patient's tolerance and age. ${ }^{60,68,69}$ Due to the potential for severe hematological side effects, laboratory monitoring is required for patients who receive dapsone. A complete differential blood count and hepatic function and renal function tests should be requested prior to the initiation of therapy, with the differential blood count repeated weekly during the first month of treatment and twice monthly for the following 2 months. Before initiating dapsone, patients should be tested for glucose-6-phosphate dehydrogenase (G6PD) deficiency. A reduction of 1 to $2 \mathrm{~g} / \mathrm{dL}$ of hemoglobin is often observed in dapsone users with normal G6PD levels. Provided that there are no significant comorbidities, patients tolerate it well. ${ }^{60,70}$

If the disease is not adequately controlled, tetracycline ( 1 to $2 \mathrm{~g}$ per day) or doxycycline $100 \mathrm{mg} /$ day and nicotinamide (2 to $3 \mathrm{~g}$ per day) may be used. The adverse effects of tetracycline include gastrointestinal discomfort and phototoxicity..$^{59,60}$

\section{Systemic corticosteroids}

Systemic corticosteroids are the first-line treatment for patients with severe, extensive, rapidly progressing MMP and those who do not respond to initial therapies. The dosage may vary depending on the patient's clinical context, and it can be started at $0.5 \mathrm{mg} / \mathrm{kg} /$ day for moderate conditions, reaching $1-2 \mathrm{mg} / \mathrm{kg} /$ day for more severe conditions. It should be administered in a single morning dose and maintained until the disease is controlled, with healing of all lesions and no emergence of new lesions. A rapid response is usually observed when treatment is started. Pulse therapy with methylprednisolone (at $500 \mathrm{mg}$ to $1 \mathrm{~g} /$ day for 3 days) has been frequently employed with good results, effecting a clinical response more rapidly. Yet, treatment may be necessary over a long period, accompanied by the risk of adverse effects of prolonged corticosteroid therapy.

Steroid-sparing immunosuppressive agents, such as azathioprine, mycophenolate mofetil, cyclophosphamide, and methotrexate, may be combined early to help maintain disease control and allow a gradual reduction in corticosteroids. Decreases of 5 to $10 \mathrm{mg}$ per week, over several weeks, are recommended. These immunosuppressive agents are maintained over the long term, whereas corticosteroids are tapered over 6 to 12 months. The ultimate goal is to administer monotherapy with an immunosuppressive agent. Topical therapy can also be maintained as adjuvant treatment throughout this regimen.

A rigorous clinical monitoring protocol is necessary for all patients during therapy. Treatment strategies are recommended to protect patients from the many adverse effects of prolonged corticotherapy. These approaches include the use of an $\mathrm{H} 2$ blocker or proton pump inhibitor for gastric ulcer prophylaxis and bisphosphonate supplementation (daily, weekly, or monthly), calcium (1000 to $1500 \mathrm{mg}$ daily), and vitamin D (800 to $1000 \mathrm{IU}$ per day) for prophylaxis of osteoporosis and strongyloidiasis before immunosuppression. ${ }^{60,67}$

\section{Immunosuppressants}

Azathioprine

Azathioprine is one of the choices for adjuvant therapy in 
MMP, as long as the disease is not progressing rapidly or is threatening vision. A delay in its introduction, up to 8 weeks, limits its initial use as monotherapy. The dose of azathioprine $(1-3 \mathrm{mg} / \mathrm{kg} /$ day $)$ should be individualized, based on the activity of thiopurine methyltransferase (TPMT), an enzyme that is involved in drug metabolism. The main side effects of azathioprine include hepatotoxicity, hypersensitivity syndrome, and neutropenia. Regular laboratory monitoring should be performed for early detection of adverse effects. ${ }^{60,67}$

\section{Mycophenolate mofetil}

Mycophenolate mofetil is an immunosuppressive agent that reversibly inhibits inosine monophosphate dehydrogenase. Unlike other cell lines, $\mathrm{T}$ and B lymphocytes depend on this pathway for purine synthesis, which is essential for cell proliferation. Its use has had good results in disease control, with a favorable safety profile and limited side effects compared with other immunosuppressants, such as azathioprine and methotrexate. ${ }^{71,72}$

Treatment with low doses should be started by gradually, increasing the dose according to the clinical effect and the appearance of adverse effects; in certain cases, it will be necessary to switch to mycophenolate sodium. The daily dosage can reach 2 to $3 \mathrm{~g} /$ day, divided into 2 doses. Once disease control is achieved and maintained for several months, mycophenolate mofetil can be reduced gradually and even discontinued. ${ }^{67}$

The most common side effects of mycophenolate mofetil are gastrointestinal complaints. But the cytopenias are the major concerns and require regular monitoring. A complete blood count with differential can be obtained at baseline and every two weeks during the first two to three months of therapy, then once monthly within the first year, and every three months thereafter. ${ }^{73}$

\section{Methotrexate}

Although the use of methotrexate is simple and although dermatologists are familiar with its administration, it is not commonly used as adjuvant therapy in mucous membrane pemphigoid. However, it can be considered as an option in patients with contraindications or those who have failed other adjuvant agents. The dose of methotrexate is more suitable for patients with mild to moderate disease. Low weekly dosages (10 to $17.5 \mathrm{mg}$ per week) have been effective and well tolerated. ${ }^{60,74}$ Folic acid supplementation helps prevent gastrointestinal adverse effects and elevated transaminase levels. Patients should be monitored regularly by laboratory testing, adjusting the dose as necessary. ${ }^{75,76}$

\section{Cyclophosphamide}

Cyclophosphamide is a rapid and effective therapeutic agent and is reserved for patients with severe, rapidly progressing disease or those who have not responded to other immunosuppressive agents. It can be administered alone $(1-2 \mathrm{mg} / \mathrm{kg} /$ day) or in combination with corticosteroids in high doses (prednisone 1-1.5mg/ $\mathrm{kg}$ per day). ${ }^{53}$ In some cases, more aggressive treatment with pulse therapy is required at $1 \mathrm{~g} /$ day or $10-15 \mathrm{mg} / \mathrm{kg} /$ day, in combination with dexamethasone $100 \mathrm{mg}$ on the first day, followed by dexamethasone only on the other 2 days; this cycle may be repeated every 26 days, depending on symptomatology. Regular laboratory moni- toring includes a complete differential blood count and urinalysis. Due to its potential toxicity, cyclophosphamide should be used as a short-term therapy and replaced with an alternative adjuvant after disease control has been achieved..$^{60,77}$

\section{Immunoglobulin}

Intravenous immunoglobulin (IVIG) is an immunomodulatory agent that is composed of polyclonal antibodies and derived from the plasma of a large group of healthy donors. Its mechanism of action is unclear; it appears to regulate the immune system in various ways. It is not a first-line treatment, but it may be beneficial for patients with severely debilitating, potentially fatal, and rapidly progressing disease. Patients who do not respond to conventional therapy, discontinue it due to severe side effects, or have contraindications are also candidates for IVIG. Immunosuppressive agents increase the risk of the reactivation of chronic infections, such as $\mathrm{HBV}$ and HCV. Therapeutic combination with IVIG reduces the risk of reactivation and contributes to clinical improvement. ${ }^{78}$

IVIG has a relatively safe response and rapid efficacy compared with conventional treatments. The suggested dose is $2 / \mathrm{kg}$ per cycle. One cycle consists of the total dose divided into equal doses over a period of 3 to 5 days. The need for subsequent cycles should be assessed according to the clinical response. ${ }^{60}$ Treated patients have shown excellent results, with significantly shorter treatment durations, fewer relapses, higher remission rates, fewer adverse effects, and better quality-of-life assessments compared with conventional therapy. ${ }^{79}$ Most patients do not have serious adverse effects, rendering the treatment safe. The major limitation of IVIG use is its high cost. ${ }^{60,78}$

\section{Rituximab}

Rituximab is a chimeric monoclonal antibody (murine and human) that is directed against CD20 on pre-B and B lymphocytes, depleting these cells from circulation for 6 to 12 months. It is not a first-line treatment, due to the absence of confirmatory studies. However, it has been used successfully for the treatment of severe pulmonary arterial hypertension, especially in patients who have not responded to conventional therapy or have had serious side effects or contraindications. A rituximab cycle is administered at a dose of $375 \mathrm{mg} / \mathrm{m}^{2}$, administered weekly for 4 consecutive weeks. IVIG, systemic corticosteroids, and other immunosuppressive agents are often given concomitantly with rituximab. After the induction cycle, long-term infusion therapy every 4 or 12 weeks may be performed or according to clinical need. ${ }^{60,80}$

The most common adverse effects are associated with infusion reactions, often related to the rate of administration and hypersensitivity reactions (fever, chills, bronchospasm, pruritus, and hypotension). Rituximab is contraindicated in pregnancy; patients of childbearing age should use effective contraception during its use and up to 12 months afterward. ${ }^{60,81}$

\section{Anti-TNF alpha agents}

In addition to conventional treatments, anti-TNF alpha agents have been reported to be effective in mucous membrane pemphigoid, perhaps merited by the high serum TNF-alpha levels 


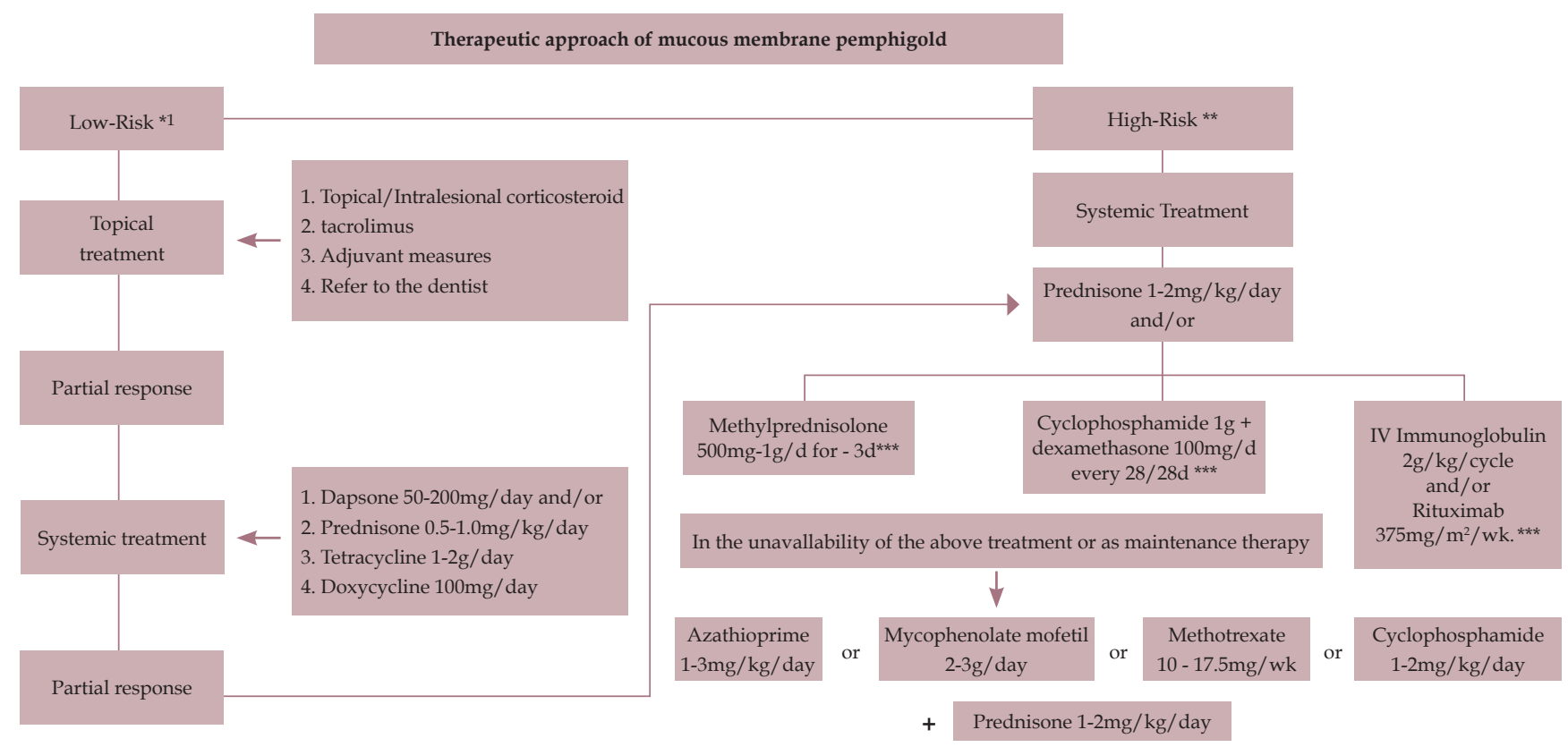

FIGURE 2: Mucous membranes pemphigoid treatment algorithm.

* Low risk: disease limited to oral mucosa with or without cutaneous involvement

**High risk: ocular, pharyngeal, laryngeal, esophageal, and/or genital lesions

*** Prednisone at a dosage of $1-2 \mathrm{mg} / \mathrm{kg} /$ day should be maintained between pulse therapy intervals

in patients. They are generally indicated for those who are in need of aggressive systemic treatment, do not respond to conventional therapy, or have severe side effects or contraindications. Several reports in the literature have demonstrated the efficacy of etanercept and infliximab. The clinical improvement after treatment with these agents supports the hypothesis that TNF-alpha plays an important role in the pathogenesis of mucous membrane pemphigoid..$^{82-84}$

\section{PROGNOSIS}

Mucous membrane pemphigoid is a chronic, often devastating, but rarely fatal disease. Even when localized, it can have a tremendous negative impact on a patient's quality of life. Its chronic inflammatory nature, tissue destruction, and scarring are responsible for the sequelae, which are often disabling. The therapeutic strategy will depend on the site, severity, and rate of progression. Patients with low risk (oral mucosa with or without cutaneous involvement) have a better prognosis and respond well to conservative approaches, whereas high-risk patients (ocular, nasopharyngeal, laryngeal, esophageal, and anogenital mucosa) have a worse prognosis, being poor responders and often experiencing scarring, despite treatment. In the latter, an early aggressive approach helps stop the inflammatory process and prevent scarring. ${ }^{53,60}$

\section{CONCLUSION}

Our experience indicates that the approach should be as aggressive as possible for high-risk patients. Some therapeutic options can be employed, depending on the clinical context and their availability. Pulse therapy with methylprednisolone, cyclophosphamide in combination with dexamethasone, and IVIG with rituximab have effected good responses in our service. In cases of unavailability, contraindications, or serious side effects to these options, prednisone $(1-2 \mathrm{mg} / \mathrm{kg} /$ day) can be administered concomitantly with such immunosuppressants as azathioprine, mycophenolate mofetil, and methotrexate, as demonstrated in the treatment flowchart (Figure 2). We believe that long-term follow-up of these patients should be performed to detect relapses and initiate early therapeutic intervention, and previous pulses or cycles may be repeated. 


\section{EPIDERMOLYSIS BULLOSA ACQUISITA}

\section{INTRODUCTION}

Epidermolysis bullosa acquisita (EBA) is an autoimmune subepidermal bullous dermatosis that affects the skin and mucous membranes, characterized by autoantibodies that are directed against type VII collagen (COLVII). ${ }^{85}$

\section{EPIDEMIOLOGY}

EBA is a rare disease, accounting for approximately $5 \%$ of autoimmune bullous diseases that target antigens in the basement membrane zone (BMZ), with an annual incidence varying between 0.08 to 0.5 cases per million individuals. ${ }^{86,87}$ EBA has no predilection for gender and can occur at any age, peaking in incidence between the fourth and fifth decades..$^{88,89}$

\section{PATHOPHYSIOLOGY}

Recent evidence shows that IgG autoantibodies against epitopes in the non-collagenous domain of COLVII are relevant in the pathogenesis of EBA. ${ }^{90} \mathrm{COLVII}$ is the main component of anchoring fibrils in the sublamina densa of the BMZ. Therefore, the involvement of these structures results in the loss of dermoepidermal adhesion, with subsequent cutaneous fragility, vesicle and blister formation, and scarring.

\section{CLINICAL PRESENTATION}

EBA has a wide spectrum of clinical presentations and can affect the skin and mucous membranes. EBA has 5 main phenotypes. ${ }^{91}$

I) The classical or mechanobullous form is observed in approximately one-third of EBA patients and is characterized by skin fragility in trauma-prone areas, with tense blisters, erosions, atrophic scars, milia formation, anonychia, and digital contracture, especially on the fingers. ${ }^{88,92}$

II) The bullous pemphigoid-like variant presents as vesicles and blisters with erythematous or urticarial lesions, usually without skin fragility or milia formation, mainly in the extremities, trunk, and skin folds. ${ }^{93}$

III) The cicatricial pemphigoid-like form presents with exclusive or predominant mucous involvement, affecting any stratified squamous cell epithelia, such as ocular, oral, nasal, laryngeal, esophageal, and genital mucosa. ${ }^{94}$

IV) The Brunsting-Perry pemphigoid-like variant is defined as a vesiculobullous eruption on the head and neck, which may eventually have oral involvement. ${ }^{95}$

V) The linear IgA bullous dermatosis-like form is characterized by edematous plaques with tense blisters and vesicules that can present in annular or polycyclic arrangement. In this form of EBA, the direct immunofluorescence demonstrates linear IgA deposition in the BMZ. ${ }^{94}$

The differential diagnosis of EBA includes bullous systemic lupus erythematosus, porphyria cutanea tarda, and other subepidermal bullous dermatosis, as mentioned in the clinical variants.

\section{DIAGNOSIS}

The diagnosis of EBA comprises histopathological analysis and direct (DIF) and indirect (IIF) immunofluorescence, which allow the diagnosis of subepidermal bullous dermatosis. However, they are not always conclusive for the diagnosis of EBA. The definite diagnosis of EBA requires additional techniques that are only available in research centers.

The histopathological evaluation of injured skin in patients with EBA shows subepidermal cleavage, with varying degrees of inflammatory infiltrate. In the mechanobullous form, the inflammatory infiltrate is absent or minimal, whereas in the inflammatory forms of EBA, it is composed of neutrophils with variable numbers of eosinophils, monocytes, and lymphocytes. ${ }^{94}$

DIF of perilesional skin reveals linear deposition of IgG and C3 along the BMZ. Occasionally, IgA and/or IgM may be present. Serration pattern analysis by DIF allows a differential diagnosis between EBA and bullous pemphigoid, which present as $\mathrm{U}$ and $\mathrm{N}$ patterns, respectively ${ }^{96} \mathrm{IIF}$ of normal human skin also identifies IgG deposits with a linear pattern in the BMZ. The salt-split skin technique, which produces BMZ cleavage in the lamina lucida, shows IgG deposition on the dermal side of the cleavage in EBA, whereas in bullous pemphigoid, this deposit is present on the epidermal or epidermal and dermal side of the cleavage.

\section{TREATMENT}

EBA is often refractory to various therapeutic modalities, which makes its long-term remission a challenge. Because it is a rare disease with several clinical presentations, there are no randomized clinical trials in the literature, compromising the selection of an ideal treatment. The inflammatory form of EBA apparently has a more favorable clinical response to conventional therapy with corticosteroids and corticosteroid-sparing agents than the mechanobullous form. ${ }^{97}$

I) Clinical and laboratory evaluation prior to immunosuppressive therapy

- Multidisciplinary evaluation for diagnosis of mucosal involvement:

- Ophthalmology

- Otolaryngology

- Gastroenterology

- Gynecology

- Evaluation of comorbidities:

- Systemic arterial hypertension

- Diabetes mellitus

- Bone evaluation (bone mineral densitometry)

- Inflammatory bowel disease

- Infectious diseases (hepatitis, Chagas disease, HIV, tuberculosis)

- Neoplasms

- Others

- Vaccination

- Stool examination

- Prophylaxis with ivermectin

- Pregnancy (pregnancy test and contraception) 


\section{II) General skin care}

Local care should be encouraged for better disease control. Similar to inherited epidermolysis bullosa, the general care includes the prevention of local trauma and infection and the use of non-adherent dressings. ${ }^{98}$

\section{III) Systemic treatment}

\section{A) Introduction}

A Cochrane systematic review found 11 non-randomized studies of treatment for EBA, involving interventions in 20 adults and 11 children..$^{99}$ Adult patients were treated with various therapeutic modalities, including systemic corticosteroids, immunosuppressants, dapsone, colchicine, and intravenous immunoglobulin. Most children were treated with systemic corticosteroids and/or dapsone. The authors concluded that there is no recommendation for treating EBA, based on reliable evidence.

\section{B) Medications}

\section{Corticosteroids}

EBA patients, especially those of the mechanobullous form usually do not experience a good therapeutic response to systemic corticosteroids, such as in other autoimmune blistering diseases.

Despite this limitation, systemic corticosteroids are still considered the first-line treatment for EBA, with usual dosages of $0.5-1.5 \mathrm{mg} / \mathrm{kg} /$ day; they can be used as monotherapy in some cases of mild disease ${ }^{100}$ A retrospective Spanish study of 12 patients with EBA showed that a dosage greater than $15 \mathrm{mg}$ /day is required to control disease activity. ${ }^{101}$ However, most patients require adjuvant treatment for better disease control or to avoid undesirable side effects of prolonged use of corticosteroids, such as obesity, hypertension, and osteoporosis. One study demonstrated that the use of methylprednisolone at a high dosage $(>8 \mathrm{mg} /$ day) led to earlier remission compared with low-dose use $(\leq 8 \mathrm{mg} /$ day) and that some patients obtained a good response to pulse therapy with methylprednisolone (500mg for 3 days). ${ }^{102}$

Anti-inflammatory agents (dapsone, colchicine, tetracycline)

The main anti-inflammatory benefits of these medications are exerted by an antineutrophilic action. ${ }^{103}$

Dapsone use has been described in several cases of EBA. ${ }^{101,102,104}$ The commonly used dosages range from $25-100 \mathrm{mg} /$ day or $1-2 \mathrm{mg} / \mathrm{kg} /$ day, with a favorable response being reported in adult and pediatric cases. ${ }^{105}$ It should be noted that unlike the condition in adults, EBA in childhood tends to have a better prognosis, usually with a good response to dapsone and systemic corticosteroid. ${ }^{106,107}$ The proposed protocols for the treatment of EBA in the literature include dapsone as one of the first therapeutic options, combined with systemic corticosteroid therapy, primarily for the mild forms of EBA. ${ }^{100,101}$ Common medication side effects include hemolysis and methemoglobinemia. ${ }^{108}$

The efficacy of colchicine in EBA was reported for the first time in 1989, with dosages ranging from $0.5-2 \mathrm{mg} /$ day. ${ }^{109}$ Among adjuvant treatments, colchicine is considered a first-line agent and is frequently associated with systemic corticosteroids. ${ }^{100}$ Although it is less common, colchicine has also been reported as a monotherapy, yielding a good clinical response ${ }^{110}$ However, its side effects, especially diarrhea, can limit its use, making it difficult to achieve a sufficient dose to control the disease in certain patients. ${ }^{111}$

Minocycline is a broad-spectrum tetracycline that inhibits the recruitment of neutrophils and eosinophils as well as cytokine production. ${ }^{112}$ A Japanese study that evaluated the clinical and immunological aspects of 105 patients with EBA described minocycline as one of the most common therapeutic options, having been used in 16 patients; however, details regarding the therapeutic response were not specified. ${ }^{91} \mathrm{~A}$ recent case report showed a patient with an inflammatory form of EBA who was treated with various therapeutic options, such as systemic corticosteroid, cyclosporine, and dapsone, responding to the combination of minocycline (200mg/day) and systemic corticosteroid. ${ }^{112}$ This study suggested that minocycline may be considered as a therapeutic option in EBA, mainly as an adjuvant in inflammatory forms of the disease.

Immunosuppressants (azathioprine, mycophenolate mofetil, cyclosporine, methotrexate)

These medications are commonly used as systemic corticosteroid-sparing agents.

Azathioprine has varying results in the literature. ${ }^{101,104,113} \mathrm{Al}-$ though its use is well established in pemphigus vulgaris, its application in EBA is less convincing, with other medications, such as dapsone and mycophenolate mofetil, being preferred more often. ${ }^{114}$

Mycophenolate mofetil (MMF) is an immunosuppressive agent that alters the proliferation of $\mathrm{B}$ and T lymphocytes. ${ }^{111}$ In EBA, MMF has been reported to be effective in some refractory cases. ${ }^{105} \mathrm{~A}$ recent study described 4 patients with EBA who were treated with MMF at 2 to $3 \mathrm{~g} /$ day, with success. ${ }^{115}$ One of the limiting factors of its use in daily practice is its high cost.

Cyclosporine is usually used at doses of $4-9 \mathrm{mg} / \mathrm{kg}$, leading to disease improvement in recalcitrant cases. ${ }^{103,105} \mathrm{~A}$ report of 2 patients with the rare association of EBA and acquired hemophilia A demonstrated a good therapeutic response with prednisone and cyclosporine, with no adverse effects. ${ }^{116}$ In addition, cyclosporine is considered a relatively safer immunosuppressive drug in pregnancy. ${ }^{114}$

Methotrexate is a folic acid analogue and antimetabolite that inhibits the synthesis of DNA and RNA, impairing lymphocyte function. ${ }^{108}$ There are no reports of monotherapy in patients with EBA and no data that documents its effectiveness as a systemic corticosteroid-sparing agent in EBA, reserving its use for refractory cases of the disease. ${ }^{92}$

\section{Intravenous immunoglobulin (IVIG)}

IVIG modulates the autoimmune response, reducing and neutralizing antibodies. ${ }^{117}$ It is usually administered at $2 \mathrm{~g} / \mathrm{kg} /$ cycle over 3 to 5 days as monotherapy or in combination with other drugs, such as systemic corticosteroid and dapsone, with good response in patients with recalcitrant disease. ${ }^{103,117}$ One long-term study evaluated 10 patients with EBA that were resistant to conventional therapy after IVIG administration, resulting in a satisfactory response in all cases. ${ }^{118}$ Patients received 16-31 IVIG cycles over 30-52 months, allowing adjuvant medications (prednisone, dapsone, and others) and, later, IVIG to be withdrawn. No disease recurrence was observed at a mean follow-up of 53.9 months after discontinuation of IVIG, suggesting that this drug leads to prolonged remission of EBA. Immunoglobulin was also administered subcutaneously in a 
patient with severe and resistant disease, which can represent an alternative in cases with difficult venous puncture. ${ }^{119}$

\section{Extracorporeal photopheresis (ECP)}

ECP is an immunomodulatory therapy that was initially used in cutaneous $\mathrm{T}$ cell lymphoma that consists on the separation of a peripheral blood leukocyte/lymphocyte-enriched cellular fraction, extracorporeal treatment of 8-MOP/UVA cells, and subsequent reinfusion of cells into the patient. ${ }^{120}$ Its main effect in EBA appears to be associated with inhibiting the production of pathogenic autoantibodies by B lymphocytes and producing regulatory T cells. ${ }^{97}$

$\mathrm{ECP}$ has proven to be efficient in inducing partial to complete remission in patients with recalcitrant EBA and is considered a well-tolerated therapy, with promising results. ${ }^{121-123}$

In the literature, a recent review revealed that 8 patients with severe and refractory EBA were treated with ECP, all of which progressed with clinical improvement. ${ }^{123}$

European guidelines on ECP states that such treatment can be used in severe and refractory cases of EBA. ${ }^{124}$

\section{Rituximab}

Rituximab is a chimeric anti-CD20 monoclonal antibody that causes B cell depletion through various mechanisms and is approved for the treatment of B cell lymphoma, rheumatoid arthritis, and granulomatosis with polyangiitis. ${ }^{125}$ In the context of autoimmune bullous diseases, its use was initially described for recalcitrant cases of pemphigus and, recently, as first-line treatment in combination with short term prednisone, being effective and potentially safer than a standard regimen of high doses of corticosteroids in patients with moderate to severe pemphigus. ${ }^{126,127}$

Rituximab use in subepidermal bullous diseases, however, is more limited. In EBA, a few promising case reports have been described, usually in patients with recalcitrant disease who have undergone several treatments before rituximab (such as systemic corticosteroid, dapsone, azathioprine, cyclosporine, mycophenolate, and cyclophosphamide), with an effective response. ${ }^{128-131}$ The therapeutic scheme was usually $375 \mathrm{mg} / \mathrm{m}^{2}$ weekly, administered over 4 weeks. Another proposed scheme is $1 \mathrm{~g}$, administered on Days 0 and 14 .

Rituximab (375mg/ $\mathrm{m}^{2}$ weekly, managed over 4 weeks), combined with IVIG $(2 \mathrm{~g} / \mathrm{kg} /$ monthly cycle), was given to 4 patients who were resistant to conventional therapy, showing an effective and efficient response. ${ }^{132}$ In addition, rituximab combined with protein A immunoadsorption has, in some cases, resulted in favorable outcomes. ${ }^{133,134}$

In the authors' personal experience, 5 patients with EBA were treated with rituximab. All patients presented with mechanobullous form, severe mucosal impairment and were resistant to conventional therapy, including systemic corticosteroid therapy (1mg/kg/day), dapsone (100mg/day), cyclosporine $(5 \mathrm{mg} / \mathrm{kg})$, azathioprine (150mg/day), and mycophenolate mofetil ( $3 \mathrm{~g} /$ day). In most cases, rituximab was administered following the rheumatoid arthritis protocol, at $1 \mathrm{~g}$ IV on Day 0 and $1 \mathrm{~g}$ IV on Day 14. All patients needed a new drug cycle after 6 months. At present, 2 patients are in complete remission, 1 is in partial remission, and 2 experienced disease relapse after being in complete remission for 1 year.

\section{IV) Classification of EBA severity}

There is no standardized severity score for EBA; 2 recent classifications have been proposed in the literature:

Classification I: ${ }^{103}$

-Mild EBA: $<5 \%$ of body surface affected, without mucosal involvement.

-Moderate EBA: $5 \%$ to $15 \%$ of body surface affected with at most 2 affected mucous membrane sites, not including ocular involvement.

-Severe EBA: $>5 \%$ of body surface affected and $>2$ mucous membrane sites involved or ocular involvement.

In mild forms of EBA, use of prednisone $(0.5-1 \mathrm{mg} / \mathrm{kg} /$ day $)$ with additional colchicine and dapsone is suggested. Prednisone (1-1.5mg/ $\mathrm{kg} /$ day) with additional colchicine is recommended for moderate EBA. Treatment suggested for severe forms of EBA involves the same as in moderate EBA, with the addition of one or a combination of steroid pulses, cyclosporine, plasmapheresis, IVIg or rituximab.

\section{Classification II:}

-Non-severe EBA: absence of severe mucosal involvement (IIC ocular, laryngeal or esophageal) or diffuse cutaneous involvement. ${ }^{135}$

-Severe EBA: presence of severe mucosal involvement - ocular, laryngeal, or esophageal.

In the non-severe localized form, topical corticosteroids are suggested, whereas in the non-severe, more diffuse form, the use of colchicine, dapsone, sulfasalazine, and topical corticosteroid is advised. In severe EBA, cyclosporine or IVIG is recommended; rituximab or ECF can be considered as an alternative. Systemic corticosteroid therapy is reserved for urgent cases, such as laryngeal edema.

The authors of this consensus propose the following classification of EBA severity:

-Non-severe EBA: up to $10 \%$ of total body surface involved without functional alteration (flexion contracture of fingers) and absence of severe mucosal involvement (ocular, laryngeal, or esophageal).

-Severe EBA: greater than $10 \%$ of total body surface area affected, and/or presence of functional alteration (flexion contracture of fingers), and/or severe mucosal involvement (ocular, laryngeal, or esophageal), or non-severe EBA that is unresponsive to the proposed treatment.

This classification was used for the treatment algorithm below.

V) Proposed treatment algorithm

In the non-severe form of EBA, the first treatment option suggested by the authors is colchicine $(0.5-2 \mathrm{mg} /$ day) or dapsone (50$100 \mathrm{mg} /$ day). If a partial response occurs, prednisone should be added at $0.5-1 \mathrm{mg} / \mathrm{kg} /$ day. If absence of clinical response and/or side effect, treatment should be replaced for prednisone $(0.5-1 \mathrm{mg} / \mathrm{kg} /$ day). (Figure 3)

In the severe form of EBA, the first treatment option suggested is IVIG $(2 \mathrm{~g} / \mathrm{kg}$ over 5 days) in combination with oral systemic corticosteroid (1-1.5mg/ $\mathrm{kg} /$ day) or pulse therapy with methylprednisolone (1g IV for 3 days). If partial or absence of response occurs, an immunosuppressant, such as mycophenolate mofetil (2-3g/day), cyclosporine $(5 \mathrm{mg} / \mathrm{kg} /$ day), or azathioprine $(100-200 \mathrm{mg} /$ day), should be introduced. In refractory cases, rituximab is suggested, at the dosage of $1 \mathrm{~g}$ IV on Days 0 and 14 or $375 \mathrm{mg} / \mathrm{m}^{2}$ weekly over 4 weeks, every 6 months. Immunosuppressive therapy (MMF, cyclosporine, or azathioprine) should be discontinued in case of no thera- 

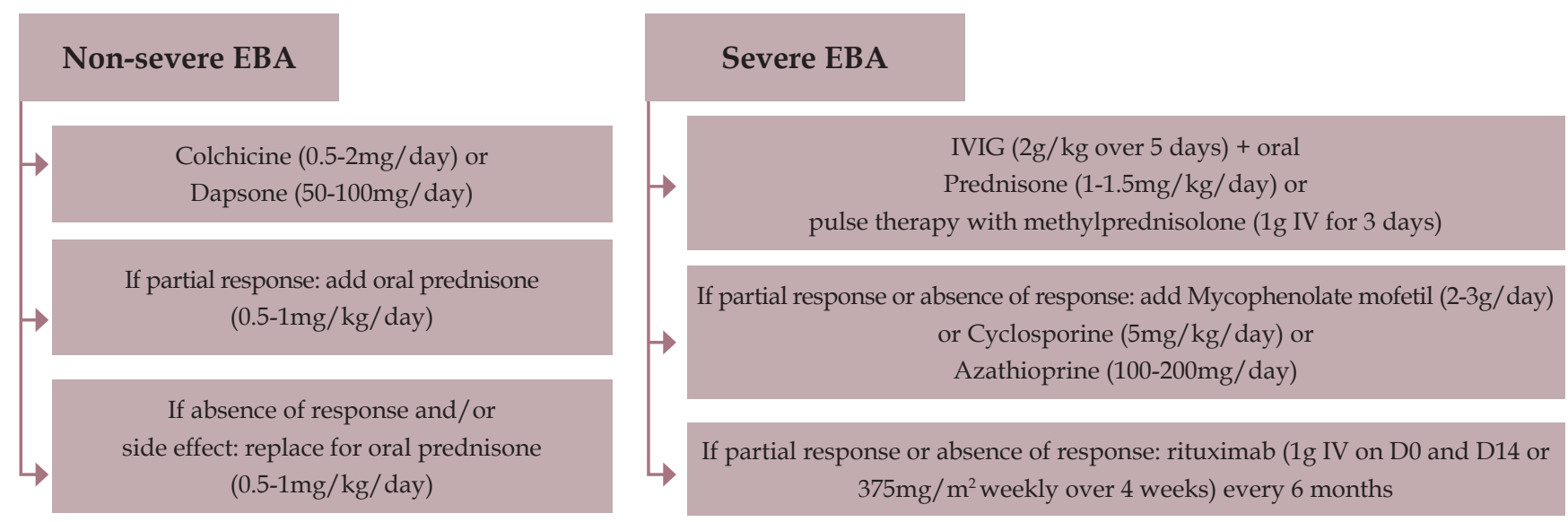

Figure 3: Proposed treatment algorithm for epidermolysis bullosa acquisita (EBA) IVIG - intravenous immunoglobulin

peutic response or side effects. In cases of partial response to such immunosuppressants, they may be maintained in combination with rituximab. However, one should consider the possible side effects of this association, especially infectious ones. The possibility of infectious prophylaxis should be considered.

Oral corticosteroids should be maintained at a dosage of $1 \mathrm{mg} / \mathrm{kg} /$ day until the development of new lesions is interrupted and pre-existing lesions begin to heal (average of 4 weeks). Afterward, a reduction of $10 \mathrm{mg}$ every 2 weeks should be made until the dose reaches approximately $0.5 \mathrm{mg} / \mathrm{kg}$. Thereafter, reductions should be made by $10 \mathrm{mg}$ every 4 weeks, according to the patient's clinical evolution. When the dosage reaches 7.5 to $5 \mathrm{mg} /$ day of prednisone, absolute care should be taken due to adrenal gland suppression. Prednisone at a dosage of $5 \mathrm{mg} /$ day should be replaced with hydrocortisone at $20 \mathrm{mg}$ at 8 hours and $10 \mathrm{mg}$ at 14 hours until the serum cortisol level exceeds $10 \mu \mathrm{g} / \mathrm{dL}$ or, ideally, $18 \mu \mathrm{g} / \mathrm{dL}$. Attention should be given to stressful situations (such as surgeries and infections), in which the dose of hydrocortisone should be doubled.

In the case of pulse therapy, at the end of 3 days, corticosteroid therapy should be maintained through oral administration of prednisone at 0.5 to $1 \mathrm{mg} / \mathrm{kg} /$ day.

\section{EVOLUTION AND PROGNOSIS}

EBA is a disease that can evolve with high morbidity due to its potential for scarring. The cutaneous involvement in EBA can progress with extensive erosions, atrophic scars, nail dystrophies, and fibrosis, with flexion contracture of fingers, limiting adequate mobility.

Different mucosal sites with stratified squamous epithelium may be affected, such as the conjunctival, upper airway, oral, esophageal, genital, and anal areas.
Ocular involvement in EBA is frequent, with various forms of presentation, including conjunctivitis, symblepharon, keratitis, subepithelial vesiculation, perforation, and corneal opacification. ${ }^{136,137}$ In severe cases, blindness may occur. ${ }^{136-138}$ Upper airway involvement can occur, with formation of synechia, erosions, thickening of the epiglottis, and supraglottic stenosis. ${ }^{139}$ Some cases result in acute airway obstruction, requiring a tracheostomy. ${ }^{139,140}$ Esophageal involvement may present as the formation of erosions and stenosis and dysphagia. ${ }^{13,141}$ Sometimes, patients must undergo periodic esophageal dilations and, in extreme cases, gastrostomy.

Mucosal involvement may occur in a silent, chronic manner and progress to life-threatening complications. ${ }^{142}$ Such impairments worsen the patients' prognosis, impacting their quality of life and requiring long-term clinical and laboratory follow-up. ${ }^{104}$ In this context, multidisciplinary follow-up becomes mandatory for the early diagnosis and detection of subclinical lesions, thus preventing subsequent severe complications. In addition, mucosal involvement may render the disease more difficult to control, requiring aggressive immunosuppressive therapy.

\section{CONCLUSION}

EBA is a rare disease with a broad clinical spectrum, making the evaluation of therapeutic results difficult. Mild forms of the disease may have a favorable response to treatment with dapsone or colchicine. Severe forms, with mucosal involvement, often subclinical, may evolve with acute and/or chronic complications with respiratory, ocular, and digestive sequelae, requiring aggressive treatments. However, no proposed therapeutic regimen has proven to be the standard for severe EBA. $\square$ 


\section{REFERENCES}

1. $\quad$ Aoki V, Maruta W, Santi CG. Dermatoses Vesicobolhosas Autoimunes. In: Belda Jr. W, Di Chiacchio N, Criado PR. Tratado de Dermatologia. 2. ed. São Paulo: Atheneu; 2014. p. 417-28.

2. Alpsoy E, Akman-Karakas A, Uzun S. Geographic variations in epidemiology of two autoimmune bullous diseases: pemphigus and bullous pemphigoid. Arch Dermatol Res. 2015;307:291-8.

3. $\quad$ Langan SM, Smeeth L, Hubbard R, Fleming KM, Smith CJ, West J. Bullous pemphigoid and pemphigus vulgaris-incidence and mortality in the UK: population based cohort study. BMJ. 2008;337:a180.

4. Christophoridis S, Büdinger L, Borradori L, Hunziker T, Merk HF, Hertl M. IgG, IgA and $\operatorname{lgE}$ autoantibodies against the ectodomain of BP180 in patients with bullous and cicatricial pemphigoid and linear IgA bullous dermatosis. Br J Dermatol. 2000;143:349-55.

5. Dimson OG, Giudice GJ, Fu CL, Van den Bergh F, Warren SJ, Janson MM, et al. Identification of a potential effector function for IgE autoantibodies in the organ-specific autoimmune disease bullous pemphigoid. J Invest Dermatol. 2003;120:784-8

6. Fang H, Zhang Y, Li N, Wang G, Liu Z. The Autoimmune Skin Disease Bullous Pemphigoid: The Role of Mast Cells in Autoantibody-Induced Tissue Injury. Front Immunol. 2018:9:407

7. Freire $\mathrm{PC}$, Muñoz $\mathrm{CH}$, Stingl $\mathrm{G}$. IgE autoreactivity in bullous pemphigoid: eosinophils and mast cells as major targets of pathogenic immune reactants. $\mathrm{Br} \mathrm{J}$ Dermatol. 2017;177:1644-53.

8. Hammers CM, Stanley JR. Mechanisms of Disease: Pemphigus and Bullous Pemphigoid. Annu Rev Pathol. 2016;11:175-97.

9. Hammers CM, Payne AS. Clinical significance of immunoglobulin $E$ in bullous pemphigoid. Br J Dermatol. 2017;177:13-4.

10. Hashimoto $\mathrm{T}$. Induced autoimmune bullous diseases. $\mathrm{Br} \mathrm{J}$ Dermatol. 2017:176:304-5

11. Hashimoto T, Tsuruta D, Ishii N. Immunoglobulin E Autoantibodies in Bullous Pemphigoid Detected by Immunoglobulin E Enzyme-Linked Immunosorbent Assays. JAMA Dermatol. 2017:153:15-7.

12. Hashimoto T, Ohzono A, Teye K, Numata S, Hiroyasu S, Tsuruta D, et al. Detection of IgE autoantibodies to BP180 and BP230 and their relationship to clinical features in bullous pemphigoid. Br J Dermatol. 2017;177:141-51.

13. Liu Z, Chen L, Zhang C, Xiang LF. Circulating anti-bullous pemphigoid 180 autoantibody can be detected in a wide clinical spectrum: A cross-sectional study. J Am Acad Dermatol. 2018. pii: S0190-9622(18)32067-X

14. Liu Y, Li L, Xia Y. BP180 Is Critical in the Autoimmunity of Bullous Pemphigoid. Front Immunol. 2017:8:1752

15. Lin L, Hwang BJ, Culton DA, Li N, Burette S, Koller BH, et al. Eosinophils Mediate Tissue Injury in the Autoimmune Skin Disease Bullous Pemphigoid. J Invest Dermatol. 2018:138:1032-43.

16. Messingham KN, Holahan HM, Frydman AS, Fullenkamp C, Srikantha R, Fairley $J A$. Human eosinophils express the high affinity lgE receptor, $F c \varepsilon R I$, in bullous pemphigoid. PLoS One. 2014;9:e107725.

17. Moriuchi $\mathrm{R}$, Nishie W, Ujiie $\mathrm{H}$, Natsuga $\mathrm{K}$, Shimizu $\mathrm{H}$. In vivo analysis of IgE autoantibodies in bullous pemphigoid: a study of 100 cases. J Dermatol Sci. 2015;78:21-5

18. Nishie W. Update on the pathogenesis of bullous pemphigoid: an autoantibodymediated blistering disease targeting collagen XVII. J Dermatol Sci. 2014;73:179-86

19. Saniklidou AH, Tighe PJ, Fairclough LC, Todd I. IgE autoantibodies and their association with the disease activity and phenotype in bullous pemphigoid: a systematic review. Arch Dermatol Res. 2018:310:11-28.

20. Ren Z, Hsu DY, Brieva J, Silverberg NB, Langan SM, Silverberg JI. Hospitalization, inpatient burden and comorbidities associated with bullous pemphigoid in the U.S.A. Br J Dermatol. 2017;176:87-99.

21. Lucariello RJ, Villablanca SE, Mascaró JM Jr, Reichel M. Association between bullous pemphigoid and malignancy: A meta-analysis. Australas J Dermatol. 2018. doi: $10.1111 /$ ajd.12764

22. Lo Schiavo A, Ruocco E, Brancaccio G. Caccavale S, Ruocco V, Wolf R. Bullous pemphigoid: etiology, pathogenesis, and inducing factors: facts and controversies. Clin Dermatol. 2013:31:391-9.

23. Bernard P, Borradori. Pemphigoid Group. In: Bolognia J.L, Jorizzo JL, Schaffer JV, editors. Dermatology. 3rd ed. Philadelphia, Pa.: Elsevier Saunders; 2012: p. 475-90.

24. Bastuji-Garin S, Joly P, Lemordant P, Sparsa A, Bedane C, Delaporte E, et al. Risk factors for bullous pemphigoid in the elderly: a prospective case-control study. J Invest Dermatol. 2011;131:637-43.

25. Jedlickova H, Hlubinka M, Pavlik T, Semradova V, Budinska E, Vlasin Z.. Bullous pemphigoid and internal diseases - A case-control study. Eur J Dermatol. 2010;20:96-101

26. Cordel N, Chosidow 0, Hellot MF, Delaporte E, Lok C, Vaillant L, et al. Neurological disorders in patients with bullous pemphigoid. Dermatology. 2007;215:187-91.
27. Lai YC, Yew YW, Lambert WC. Bullous pemphigoid and its association with neurological diseases: a systematic review and meta-analysis. J Eur Acad Dermatol Venereol. 2016:30:2007-15.

28. Tarazona MJ, Mota AN, Gripp AC, Unterstell N, Bressan AL. Bullous pemphigoid and neurological disease: statistics from a dermatology service. An Bras Dermatol. 2015;90:280-2.

29. Teixeira VB, Cabral R, Brites MM, Vieira R, Figueiredo A. Bullous pemphigoid and comorbidities: a case-control study in Portuguese patients. An Bras Dermatol. 2014:89:274-8.

30. Taghipour K, Chi CC, Bhogal B, Groves RW, Venning V, Wojnarowska F. Immunopathological characteristics of patients with bullous pemphigoid and neurological disease. J Eur Acad Dermatol Venereol. 2014;28:569-73.

31. Vernal S, Julio T, Cruz F, Turatti A, Ishii N, Hashimoto T, et al. Bullous Pemphigoid Associated with Ischemic Cerebrovascular Accident and Dementia: Exclusive Blistering Lesions on the Upper Hemiparetic Limb. Acta Dermatovenerol Croat. 2018;26:179-82.

32. Milani-Nejad N, Zhang M, Kaffenberger J. The association between bullous pemphigoid and neurological disorders: a systematic review. Eur J Dermatol. 2017;27:472-81.

33. Försti AK, Huilaja L, Schmidt E, Tasanen K. Neurological and psychiatric associations in bullous pemphigoid-more than skin deep? Exp Dermatol. 2017;26:1228-34.

34. Ali A, Hu L, Zhao F, Qiu W, Wang P, Ma X, et al. BPAG1, a distinctive role in skin and neurological diseases. Semin Cell Dev Biol. 2017;69:34-96

35. Kokkonen N, Herukka SK, Huilaja L, Kokki M, Koivisto AM, Hartikainen $P$ et al. Increased Levels of the Bullous Pemphigoid BP180 Autoantibody Are Associated with More Severe Dementia in Alzheimer's Disease. J Invest Dermatol. 2017; $137: 71-6$

36. Julio TA, Vernal S, Massaro JD, Silva MC, Donadi EA, Moriguti JC, et al. Biologica predictors shared by dementia and bullous pemphigoid patients point out a cross-antigenicity between BP180/BP230 brain and skin isoforms. Immunol Res. 2018;66:567-76.

37. Chagury AA, Sennes LU, Gil JM, Kalil J, Rodrigues H, Rosales CB, et al. HLA-C*17, DQB1*03:01, DQA1*01:03 and DQA1*05:05 Alleles Associated to Bullous Pemphigoid in Brazilian Population. Ann Dermatol. 2018;30:8-12.

38. Amber KT, Zikry J, Hertl M. A multi-hit hypothesis of bullous pemphigoid and associated neurological disease: Is HLA-DQB1*03:01, a potential link between immune privileged antigen exposure and epitope spreading? HLA. 2017;89:127-34

39. Schmidt E, Zillikens D. Pemphigoid diseases. Lancet. 2013;381:320-32

40. Arbache ST, Nogueira TG, Delgado L, Miyamoto D, Aoki V. Immunofluorescence testing in the diagnosis of autoimmune blistering diseases: overview of 10-year experience. An Bras Dermatol. 2014:89:885-9.

41. Ishii K. Importance of serological tests in diagnosis of autoimmune blistering diseases. J Dermatol. 2015;42:3-10.

42. Julio T, Vernal S, Turatti A, Roselino AM. Anti-desmogleins autoantibodies detected by ELISA and blotting in bullous pemphigoid: what do they mean? Int $J$ Dermatol. 2018:57:124-7

43. Feliciani C, Joly P, Jonkman MF, Zambruno G, Zillikens D, loannides D, et al Management of bullous pemphigoid: the European Dermatology Forum consensus in collaboration with the European Academy of Dermatology and Venereology. $\mathrm{Br} J$ Dermatol. 2015:172:867-77.

44. Brulefert A, Le Jan S, Plée J, Durlach A, Bernard P, Antonicelli F, et al. Variation of the epidermal expression of glucocorticoid receptor-beta as potential predictive marker of bullous pemphigoid outcome. Exp Dermatol. 2017;26:1261-6.

45. Kubin ME, Hellberg L, Palatsi R. Glucocorticoids: The mode of action in bullous pemphigoid. Exp Dermatol. 2017:26:1253-60.

46. Gual A, Iranzo P, Mascaró JM Jr. Treatment of bullous pemphigoid with lowdose oral cyclophosphamide: a case series of 20 patients. J Eur Acad Dermatol Venereol. 2014;28:814-8.

47. Schmidt E, Spindler V, Eming R, Amagai M, Antonicelli F, Baines JF, et al. Meeting Report of the Pathogenesis of Pemphigus and Pemphigoid Meeting in Munich, September 2016. J Invest Dermatol. 2017:137:1199-203.

48. Shetty S, Ahmed AR. Treatment of bullous pemphigoid with rituximab: critical analysis of the current literature. J Drugs Dermatol. $2013 ; 12: 672-7$.

49. Ludwig RJ, Kalies K, Köhl J, Zillikens D, Schmidt E. Emerging treatments for pemphigoid diseases. Trends Mol Med. 2013;19:501-12.

50. LazarovaZ, Yancey K. Cicatricial pemphigoid: immunopathogenesis and treatment. Derm Ther. 2002;15:382-8

51. Kridin K. Subepidermal autoimmune bullous diseases: overview, epidemiology, and associations. Immunol Res. 2018;66:6-17.

52. Kourosh AS, Yancey KB. Pathogenesis of mucous membrane pemphigoid. Dermatol Clin. 2011;29:479-84

53. Chan LS, Ahmed AR, Anhalt GJ, Bernauer W, Cooper KD, Elder MJ, et al. The first international consensus on mucous membrane pemphigoid: definition, diagnostic 
criteria, pathogenic factors, medical treatment, and prognostic indicators. Arch Dermatol. 2002;138:370-9.

54. Kasperkiewicz M, Zillikens D, Schmidt E. Pemphigoid diseases: pathogenesis, diagnosis, and treatment. Autoimmunity. 2012;45:55-70.

55. Xu HH, Werth VP, Parisi E, Sollecito TP. Mucous Membrane Pemphigoid. Dent Clin North Am. 2013;57:611-30.

56. Chan LS. Mucous membrane pemphigoid. Clin Dermatol. 2001;19:703-11.

57. Parisi E, Raghavendra S, Werth VP, Sollecito TP. Modification to the approach of the diagnosis of mucous membrane pemphigoid: A case report and literature review. Oral Surg Oral Med Oral Pathol Oral Radiol Endod. 2003;95:182-6.

58. Barbosa Ldo N, Silva RS, Verardino GC, Gripp AC, Alves Mde F. Mucous membrane pemphigoid with severe esophageal stricture. An Bras Dermatol. 2011;86:565-8.

59. Murrell DF, Marinovic B, Caux F, Prost C, Ahmed R, Wozniak K, et al. Definitions and outcome measures for mucous membrane pemphigoid: recommendations of an international panel of experts. J Am Acad Dermatol. 2015;72:168-74.

60. Knudson RM, Kalaaji AN, Bruce AJ. The management of mucous membrane pemphigoid and pemphigus. Dermatol Ther. 2010;23:268-80.

61. Gonzalez-Moles MA, Ruiz-Avila I, Rodriguez-Archilla A, Morales-Garcia P, MesaAguado F, Bascones-Martinez A, et al. Treatment of severe erosive gingival lesions by topical application of clobetasol propionate in custom trays. Oral Surg Oral Med Oral Pathol Oral Radiol Endod. 2003;95:688-92.

62. Gilbert SC. Management and prevention of recurrent herpes labialis in immunocompetent patients. Herpes. 2007;14:56-61.

63. Cernik C, Gallina K, Brodell RT. The treatment of herpes simplex infections: an evidence-based review. Arch Intern Med. 2008;168:1137-44.

64. Assmann T, Becker J, Ruzicka T, Megahed M. Topical tacrolimus for oral cicatricial pemphigoid. Clin Exp Dermatol. 2004;29:674-6.

65. Suresh L, Martinez Calixto LE, Radfar L. Successful treatment of mucous membrane pemphigoid with tacrolimus. Spec Care Dentist. 2006;26:66-70.

66. Lee HY, Blazek C, Beltraminelli H, Borradori L.. Oral mucous membrane pemphigoid: complete response to topical tacrolimus. Acta Derm Venereol. 2011;91:604-5

67. Kourosh AS, Yancey KB. Therapeutic approaches to patients with mucous membrane pemphigoid. Dermatol Clin. 2011;29:637-41.

68. Arash A, Shirin L. The management of oral mucous membrane pemphigoid with dapsone and topical corticosteroid. J Oral Pathol Med. 2008;37:341-4.

69. Gürcan HM, Ahmed AR. Efficacy of dapsone in the treatment of pemphigus and pemphigoid: analysis of current data. Am J Clin Dermatol. 2009;10:383-96.

70. Hegarty AM, Ormond M, Sweeney M, Hodgson T. Dapsone efficacy and adverse events in the management of mucous membrane pemphigoid. Eur J Dermatol. 2010;20:223-4

71. Megahed M, Schmiedeberg S, Becker J, Ruzicka T. Treatment of cicatricial pemphigoid with mycophenolate mofetil as a steroid-sparing agent. J Am Acad Dermatol. 2001:45:256-9.

72. Nottage JM, Hammersmith KM, Murchison AP, Felipe AF, Penne R, Raber I. Treatment of mucous membrane pemphigoid with mycophenolate mofetil. Cornea. 2013:32:810-5

73. Perlis C, Pan TD, McDonald CJ. Cytotoxic agents. In: Wolverton SE, editor Comprehensive Dermatologic Drug Therapy. 2nd ed. Philadelphia: Elsevier Inc 2007. p.197

74. McCluskey P, Chang JH, Singh R, Wakefield D. Methotrexate therapy for ocular cicatricial pemphigoid. Ophthalmology. 2004;111:796-801.

75. Neff AG, Turner M, Mutasim DF. Treatment strategies in mucous membrane pemphigoid. Ther Clin Risk Manag. 2008;4:617-26.

76. Prey S, Paul C. Effect of folic or folinic acid supplementation on methotrexateassociated safety and efficacy in inflammatory disease: a systematic review. $\mathrm{Br}$ Dermatol. 2009;160:622-8.

77. Munyangango EM, Le Roux-Villet C, Doan S, Pascal F, Soued I, Alexandre M, et al. Oral cyclophosphamide without corticosteroids to treat mucous membrane pemphigoid. Br J Dermatol. 2013;168:381-90.

78. Tavakolpour $\mathrm{S}$. The role of intravenous immunoglobulin in treatment of mucous membrane pemphigoid: A review of literature. J Res Med Sci. 2016;21:37.

79. Ahmed AR, Colón JE.. Comparison between intravenous immunoglobulin and conventional immunosuppressive therapy regimens in patients with severe ora pemphigoid: effects on disease progression in patients nonresponsive to dapsone therapy. Arch Dermatol. 2001;137:1181-9.

80. Le Roux-Villet C, Prost-Squarcioni C, Alexandre M, Caux F, Pascal F, Doan S, et al. Rituximab for patients with refractory mucous membrane pemphigoid. Arch Dermatol. 2011:147:843-9.

81. Bomm L, Fracaroli TS, Sodré JL, Bressan A, Gripp AC. Off-label use of rituximab in dermatology: pemphigus treatment. An Bras Dermatol. 2013;88:676-8.

82. Sacher C, Rubbert A, König C, Scharffetter-Kochanek K, Krieg T, Hunzelmann $\mathrm{N}$. Treatment of recalcitrant cicatricial pemphigoid with the tumor necrosis factor alpha antagonist etanercept. J Am Acad Dermatol. 2002;46:113-5.
83. Canizares MJ, Smith DI, Conners MS, Maverick KJ, Heffernan MP. Successful treatment of mucous membrane pemphigoid with etanercept in 3 patients. Arch Dermatol. 2006;142:1457-61.

84. Heffernan MP, Bentley DD. Successful treatment of mucous membrane pemphigoid with infliximab. Arch Dermatol. 2006;142:1268-70.

85. Lehman JS, Camilleri MJ, Gibson LE. Epidermolysis bullosa acquisita: concise review and practical considerations. Int J Dermatol. 2009;48:227-35;

86. Zhu XJ, Niimi Y, Bystryn JC. Epidermolysis bullosa acquisita. Incidence in patients with basement membrane zone antibodies. Arch Dermatol. 1990;126:171-4

87. Kridin K. Subepidermal autoimmune bullous diseases: overview, epidemiology, and associations. Immunol Res. 2018;66:6-17.

88. Kim JH, Kim SC. Epidermolysis bullosa acquisita. J Eur Acad Dermatol Venereol. 2013;27:1204-13

89. Gupta R, Woodley DT, Chen M. Epidermolysis bullosa acquisita. Clin Dermatol. 2012:30:60-9.

90. Kasperkiewicz M, Sadik CD, Bieber K, Ibrahim SM, Manz RA, Schmidt E, et al. Epidermolysis Bullosa Acquisita: From Pathophysiology to Novel Therapeutic Options. J Invest Dermatol. 2016;136:24-33

91. Hashimoto T, Jin Z, Ishii N. Clinical and immunological studies for 105 Japanese seropositive patients of epidermolysis bullosa acquisita examined at Kurume University. Expert Rev Clin Immunol. 2016;12:895-902

92. Ludwig RJ. Clinical presentation, pathogenesis, diagnosis, and treatment of epidermolysis bullosa acquisita. ISRN Dermatol. 2013;2013:812029.

93. Chen M, Kim GH, Prakash L, Woodley DT. Epidermolysis bullosa acquisita: autoimmunity to anchoring fibril collagen. Autoimmunity. 2012;45:91-101

94. Vorobyev A, Ludwig RJ, Schmidt E. Clinical features and diagnosis of epidermolysis bullosa acquisita. Expert Rev Clin Immunol. 2017;13:157-69.

95. Asfour L, Chong H, Mee J, Groves R, Singh M. Epidermolysis Bullosa Acquisita (Brunsting-Perry Pemphigoid Variant) Localized to the Face and Diagnosed With Antigen Identification Using Skin Deficient in Type VII Collagen. Am J Dermatopathol. 2017;39:e90-e96.

96. M Meijer JM, Atefi I, Diercks GFH, Vorobyev A, Zuiderveen J, Meijer HJ, et al. Serration pattern analysis for differentiating epidermolysis bullosa acquisita from other pemphigoid diseases. J Am Acad Dermatol. 2018;78:754-9.e6.

97. Mehren CR, Gniadecki R. Epidermolysis bullosa acquisita: current diagnosis and therapy. Dermatol Reports. 2011;3:e38.

98. Pope E, Lara-Corrales I, Mellerio J, Martinez A, Schultz G, Burrell R, et al. A consensus approach to wound care in epidermolysis bullosa. J Am Acad Dermatol. 2012;67:904-17.

99. Kirtschig G, Murrell D, Wojnarowska F, Khumalo N. Interventions for mucous membrane pemphigoid and epidermolysis bullosa acquisita. C Cochrane Database Syst Rev. 2003:CD004056.

100. Ishii N, Hamada T, Dainichi T, Karashima T, Nakama T, Yasumoto S, et al. Epidermolysis bullosa acquisita: what's new? J Dermatol. 2010;37:220-30.

101. Iranzo P, Herrero-González JE, Mascaró-Galy JM, Suárez-Fernández R, España A. Epidermolysis bullosa acquisita: a retrospective analysis of 12 patients evaluated in four tertiary hospitals in Spain. Br J Dermatol. 2014;171:1022-30

102. Kim JH, Kim YH, Kim SC. Epidermolysis bullosa acquisita: a retrospective clinical analysis of 30 cases. Acta Derm Venereol. 2011:91:307-12.

103. Intong LR, Murrell DF. Management of epidermolysis bullosa acquisita. Dermatol Clin. 2011;29:643-7

104. Delgado L, Aoki V, Santi C, Gabbi T, Sotto M, Maruta C. Clinical and immunopathological evaluation of epidermolysis bullosa acquisita. Clin Exp Dermatol. 2011;36:12-8

105. Gürcan HM, Ahmed AR. Current concepts in the treatment of epidermolysis bullosa acquisita. Expert Opin Pharmacother. $2011 ; 12: 1259-68$.

106. Goyal N, Rao R, Balachandran C, Pai S, Bhogal BS, Schmidt E, et al. Childhood Epidermolysis Bullosa Acquisita: Confirmation of Diagnosis by Skin Deficient in Type VII Collagen, Enzyme-linked Immunosorbent Assay, and Immunoblotting. Indian J Dermatol. 2016:61:329-32.

107. Yang B, Wang C, Wang N, Pan F, Chen S, Zhou G, et al. Childhood epidermolysis bullosa acquisita: report of a Chinese case. Pediatr Dermatol. 2012;29:614-7.

108. Mutasim DF. Autoimmune bullous dermatoses in the elderly: an update on pathophysiology, diagnosis and management. Drugs Aging. 2010;27:1-19.

109. D Dasgeb B, Kornreich D, McGuinn K, Okon L, Brownell I, Sackett DL. Colchicine: an ancient drug with novel applications. Br J Dermatol. 2018;178:350-6

110. Adachi A, Komine M, Suzuki M, Murata S, Hirano T, Ishii N, et al. Oral colchicine monotherapy for epidermolysis bullosa acquisita: Mechanism of action and efficacy. J Dermatol. 2016;43:1389-91.

111. Culton DA, Diaz LA. Treatment of subepidermal immunobullous diseases. Clin Dermatol. 2012;30:95-102.

112. Kawase K, Oshitani Y, Mizutani Y, Shu E, Fujine E, Seishima M. Inflammatory epidermolysis bullosa acquisita effectively treated with minocycline. Acta Derm Venereol. 2014;94:615-6. 
113. Tu J, Kumarasinghe PW. Epidermolysis bullosa acquisita with moderately severe Dysphagia due to esophageal strictures. Indian J Dermatol. 2011;56:224-7.

114. Meurer M. Immunosuppressive therapy for autoimmune bullous diseases. Clin Dermatol. 2012;30:78-83.

115. Sami N. Mycophenolate mofetil (MMF) in the treatment of epidermolysis bullosa acquisita (EBA) long-term follow-up. JAAD Case Rep. 2015;1:321-3.

116. Yan TM, He CX, Hua BL, Li L, Jin HZ, Liu YH, et al. Coexistence of acquired hemophilia $A$ and epidermolysis bullosa acquisita: Two case reports and published work review. J Dermatol. 2017:44:76-9.

117. Mosqueira CB, Furlani Lde A, Xavier AF, Cunha PR, Galvão AM. Intravenous immunoglobulin for treatment of severe acquired bullous epidermolysis refractory to conventional immunosuppressive therapy. An Bras Dermatol. 2010;85:521-4.

118. Ahmed AR, Gürcan HM. Treatment of epidermolysis bullosa acquisita with intravenous immunoglobulin in patients non-responsive to conventional therapy: clinical outcome and post-treatment long-term follow-up. J Eur Acad Dermatol Venereol. 2012;26:1074-83.

119. Tayal U, Burton J, Dash C, Wojnarowska F, Chapel H. Subcutaneous immunoglobulin therapy for immunomodulation in a patient with severe epidermolysis bullosa acquisita. Clin Immunol. 2008;129:518-9.

120. Sanli H, Akay BN, Ayyildiz E, Anadolu R, Ilhan 0. Remission of severe autoimmune bullous disorders induced by long-term extracorporeal photochemotherapy. Transfus Apher Sci. 2010;43:353-9.

121. Baroudjian B, Le Roux-Villet C, Bréchignac S, Alexandre M, Caux F, ProstSquarcioni C, et al. Long-term efficacy of extracorporeal photochemotherapy in a patient with refractory epidermolysis bullosa acquisita. Eur J Dermatol. 2012;22:795-7

122. Liszewski W, Omland SH, Gniadecki R. The successful use of extracorporea photopheresis in a 12-year-old patient with refractory epidermolysis bullosa acquisita. Pediatr Dermatol. 2015;32:e60-1.

123. Adamski J, Kinard $\mathrm{T}$, Ipe $\mathrm{T}$, Cooling L. Extracorporeal photopheresis for the treatment of autoimmune diseases. Transfus Apher Sci. 2015:52:171-82.

124. Knobler R, Berlin G, Calzavara-Pinton P, Greinix H, Jaksch P, Laroche L, et al Guidelines on the use of extracorporeal photopheresis. J Eur Acad Dermatol Venereol. 2014;28(Suppl 1):1-37

125. Lamberts A, Euverman HI, Terra JB, Jonkman MF, Horváth B. Effectiveness and Safety of Rituximab in Recalcitrant Pemphigoid Diseases. Front Immunol. 2018;9:248.

126. Joly P, Maho-Vaillant M, Prost-Squarcioni C, Hebert V, Houivet E, Calbo S, et al. First-line rituximab combined with short-term prednisone versus prednisone alone for the treatment of pemphigus (Ritux 3): a prospective, multicentre, parallelgroup, open-label randomised trial. Lancet. 2017;389:2031-2040

127. Hebert V, Joly P. Rituximab in pemphigus. Immunotherapy. 2018;10:27-37.

128. Saha M, Cutler T, Bhogal B, Black MM, Groves RW. Refractory epidermolysis bullosa acquisita: successful treatment with rituximab. Clin Exp Dermatol. 2009;34:e979-80

129. Kim JH, Lee SE, Kim SC. Successful treatment of epidermolysis bullosa acquisita with rituximab therapy. J Dermatol. 2012;39:477-9.

130. McKinley SK, Huang JT, Tan J, Kroshinsky D, Gellis S. A case of recalcitrant epidermolysis bullosa acquisita responsive to rituximab therapy. Pediatr Dermatol 2014;31:241-4

131. Cavailhes A, Balme B, Gilbert D, Skowron F. Successful use of combined corticosteroids and rituximab in the treatment of recalcitrant epidermolysis bullosa acquisita. Ann Dermatol Venereol. 2009;136:795-9

132. Oktem A, Akay BN, Boyvat A, Kundakci N, Erdem C, Bostancı S, et al. Longterm results of rituximab-intravenous immunoglobulin combination therapy in patients with epidermolysis bullosa acquisita resistant to conventional therapy. $\mathrm{J}$ Dermatolog Treat. 2017;28:50-4.

133. Kubisch I, Diessenbacher P, Schmidt E, Gollnick H, Leverkus M. Premonitory epidermolysis bullosa acquisita mimicking eyelid dermatitis: successful treatment with rituximab and protein A immunoapheresis. Am J Clin Dermatol. 2010;11:289-93.

134. Kolesnik M, Becker E, Reinhold D, Ambach A, Heim MU, Gollnick H, et al. Treatment of severe autoimmune blistering skin diseases with combination of protein A immunoadsorption and rituximab: a protocol without initial high dose or pulse steroid medication. J Eur Acad Dermatol Venereol. 2014;28:771-80.

135. Prost-Squarcioni C, Ingen-Housz-Oro S, Joly P, Bernard P, Bedane C; Centres de référence des maladies bulleuses auto-immunes. Société Française deDermatologie. Epidermolysis bullosa acquisita. Guidelines for the diagnosis and treatment. Centres deréférence des maladies bulleuses auto-immunes. Société Française de Dermatologie. Ann Dermatol Venereol. 2011;138:274-9.

136. Bauer JW, Schaeppi H, Metze D, Muss W, Pohla-Gubo G, Hametner R, et al. Ocular involvement in IgA-epidermolysis bullosa acquisita. B Br J Dermatol. 1999;141:887-92

137. Caux F, Kirtschig G, Lemarchand-Venencie F, Venencie PY, Hoang-Xuan T, Robin $\mathrm{H}$, et al. IgA-epidermolysis bullosa acquisita in a child resulting in blindness. $\mathrm{Br} \mathrm{J}$ Dermatol. 1997;137:270-5

138. Lang PG Jr, Tapert MJ. Severe ocular involvement in a patient with epidermolysis bullosa acquisita. JJ Am Acad Dermatol. 1987:16:439-43.

139. Benton EC, Bhogal B, Oakley R, Groves RW. Beware the blistering patient with dysphonia. Clin Exp Dermatol. 2013;38:691-2.

140. Clement M, Ratnesar P, Thirumoorthy T, McGrath J, Black MM. Epidermolysis bullosa acquisita--a case with upper airways obstruction requiring tracheostomy and responding to cyclosporin. Clin Exp Dermatol. 1993;18:548-51.

141. Ishii N, Furumura M, Hamada T, Mori 0, Ohzono A, Ueda A, et al. Oesophageal involvement in epidermolysis bullosa acquisita. Br J Dermatol. 2015;172:288-90.

142. Luke MC, Darling TN, Hsu R, Summers RM, Smith JA, Solomon BI, et al. Mucosal morbidity in patients with epidermolysis bullosa acquisita. Arch Dermatol. 1999;135:954-9.

\footnotetext{
AUTHORS'CONTRIBUTIONS

Claudia Giuli Santi (iD) ORCID 0000-0003-3650-4254

Approval of the final version of the manuscript; conception and planning of the study; elaboration and writing of the manuscript; Critical review of the literature; Critical review of the manuscript

Alexandre Carlos Gripp

D ORCID 0000-0003-2217-6704

Elaboration and writing of the manuscript; critical review of the literature; critical review of the manuscript

Ana Maria Roselino $\quad$ (iD) ORCID 0000-0002-2709-1825

Elaboration and writing of the manuscript; critical review of the literature; critical review of the manuscript

Danielle Santana Mello $\quad$ (iD) ORCID 0000-0001-5458-1451

Elaboration and writing of the manuscript; critical review of the literature; critical review of the manuscript

Juliana Olivieri Gordilho $\quad$ (D) ORCID 0000-0003-3447-5808

Elaboration and writing of the manuscript; critical review of the literature; critical review of the manuscript

Paula Figueiredo De Marsillac $\quad$ (ID) ORCID 0000-0002-0081-654X

Elaboration and writing of the manuscript; critical review of the literature; critical review of the manuscript

$\begin{array}{lll}\text { Adriana Maria Porro } & \text { (iD) ORCID } 0000-0003-0736-4790\end{array}$

Approval of the final version of the manuscript; conception and planning of the study; elaboration and writing of the manuscript; Critical review of the literature; Critical review of the manuscript
}

How to cite this article: Santi CG, Gripp AC, Roselino AM, Mello DS, Gordilho JO, Marsillac PF, Porro AM. Consensus on the treatment of autoimmune bullous dermatoses: bullous pemphigoid, mucous membrane pemphigoid and epidermolysis bullosa acquisita - Brazilian Society of Dermatology. An Bras Dermatol. 2019;94(2 Suppl 1):S33-47. 